\title{
The Radiation Induced Migration of Human Malignant Glioma Cells can be Blocked by Inhibition of the EGFR Downstream Pathways
}

Anja Pickhard ${ }^{1 *}$, Johanna Margraf ${ }^{1}$, Guido Piontek ${ }^{1}$, Andreas Knopf ${ }^{1}$, Rudolf Reiter ${ }^{2}$, Anne-Laure Boulesteix ${ }^{3}$ and Jürgen Schlegel ${ }^{4}$

${ }^{1} \mathrm{Hals}$, Nose and Throat Clinic, University of California, Ismaninger Strasse 22, 81675 Munich

${ }^{2}$ Ear, Nose and Throat Clinic, University of Ulm, Department of Speech Pathology and Audiology, Prittwitzstraße 43, 89070 Ulm

${ }^{3}$ Institut for Medical Informatics, Biometry and Epidemiology, Ludwig-Maximilians-University Munich, Marchioninistraße 15, 81377 Munich

${ }^{4}$ Institut General Pathology and Pathological Anatomy, University of California, Ismaninger Strasse 22, 81675 Munich

\begin{abstract}
Background: It is well documented that low dose ionizing radiation induces migration of glioma cells, but the mechanisms are still poorly understood. The aim of the current study was to elucidate the intracellular signal transduction pathways of radiation induced migration in human glioma cells.

Methods: Migration was assessed via a wound healing assay. In addition, tumor cell proliferation was evaluated with a MTT colorimeritric assay using 3 glioma cell lines (LN18, LN229, LNZ308). The cells were treated with increasing doses of irradiation ( $2 \mathrm{~Gy}, 5 \mathrm{~Gy}, 8 \mathrm{~Gy})$ in the presence or absence of EGF or inhibitors of the EGFR or downstream pathways (AG1478, LY294002, PD98059). Biochemical activation of EGFR, Akt/PKB and MAPK/ERK was examined by Western blot analysis.

Results: Irradiation induced a dose dependant intense increase of migrating cells and a decrease of proliferation. The inhibition of PI3K by LY294002 $(50 \mu \mathrm{mol} / \mathrm{L})$ reduced the radiation-induced migration (LN18: $p<0.001$, LN229: $p=0.16$, LNZ308: $p=0.13)$, the blockade of MEK1 by PD98059 $(50 \mu \mathrm{mol} / L)$ was also effective (LN18: $p=0.036$, LN229: $p=0.021$, LNZ308: $p=0.021$ ). After irradiation, no effect on EGFR or the downstream pathways was observed in Western blot analysis.
\end{abstract}

Conclusion: Our results demonstrate that the downstream pathways of EGFR are involved in radiation induced migration of glioma cells.

Keywords: EGFR; Radiation; Migration; Glioma

\section{Introduction}

Astrocytoma is the most frequent tumor in the central nervous system. Malignant glioblastomas are the end point of astrozytoma tumor progression. This tumor entity has a high morbidity and lethality with an overall survival of less than one year after diagnosis [1]. Key biological features of glioblastoma are excessive proliferation, disseminated tumor growth, resistance towards apoptotic stimuli, neovascularization, and suppression of antitumor immune surveillance. After surgical therapy, involved-field radiotherapy is the most important therapeutic option. This therapy prolongs the average survival for 6-8 month [2]. Recently, concomitant and adjuvant chemoradiotherapy with temozolomide has become the standard treatment for newly diagnosed glioblastoma [3]. Targeted therapy itself is confounded by the heterogeneous expression of drug targets, however several active agents have been identified, bevacizumab, cilengitide and cediranib. All of these agents have undergone multiple clinical trials and have demonstrated benefits for patients [4]. Radiosensitization is a new therapeutic strategy in the treatment of malignant gliomas. Still, it has been shown that sublethal irradiation of glioma cells promotes migration and invasiveness [5].

The epidermal growth factor receptor (EGFR) is important for proliferation in glioma cells [6,7]. Amplification of the EGF-gene is correlated with a poor prognosis [8]. The intracellular signaling pathways of the EGF-receptor are the phosphoinositide 3-kinase (PI3K) signaling pathway and the mitogen-activated-protein kinases (MAPK) pathway. Both play an important role in tumor biology [9]. The PI3K signaling pathway is frequently aberrantly activated in glioblastoma multiforme by mutation or loss of the 3' phospholipid phosphatase PTEN and has been shown to play an important role in cellular migration [10].
The aim of the current study was to investigate the signal pathways of irradiation induced migration of glioma cells. Therefore, we investigated the role of the EGFR and the downstream PI3K and MAPK signaling pathways and their impact on migration and proliferation.

\section{Material and Methods}

\section{Cell culture and irradiation}

The cell lines LN18, LN229 and LNZ308, described previously were used [11]. Cells were grown in Dulbecco's Modified Eagle Medium (DMEM) (Invitrogen, Karlsruhe, Germany) with $10 \%$ fetal calf serum, $2 \mathrm{mM}$ glutamine, and $100 \mu \mathrm{g} / \mathrm{ml}$ penicillin/streptomycin and maintained at $37^{\circ} \mathrm{C}$ in an atmosphere of $5 \% \mathrm{CO}_{2}$ to $70-90 \%$ confluence and irradiated in a linear particle accelerator (MX2, Siemens; Erlangen, Germany) at 2Gy, 5Gy and $8 \mathrm{~Gy}$. Therefore, the cell culture plates were placed between two perspex-glasses. After irradiation cells were cultured for another 24 hours.

*Corresponding author: Dr. Anja Pickhard, Klinikum rechts der Isar, ear, nose and throat clinic, 81675 Munich, Tel: 089-41405319; Fax: 089-41404952, E-mail: a.pickhard@Irz.tum.de

Received August 10, 2012; Accepted August 27, 2012; Published August 30, 2012

Citation: Pickhard A, Margraf J, Piontek G, Knopf A, Reiter R, et al. (2012) The Radiation Induced Migration of Human Malignant Glioma Cells can be Blocked by Inhibition of the EGFR Downstream Pathways. J Nucl Med Radiat Ther 3:138. doi:10.4172/2155-9619.1000138

Copyright: (C) 2012 Pickhard A, et al. This is an open-access article distributed under the terms of the Creative Commons Attribution License, which permits unrestricted use, distribution, and reproduction in any medium, provided the original author and source are credited. 
Citation: Pickhard A, Margraf J, Piontek G, Knopf A, Reiter R, et al. (2012) The Radiation Induced Migration of Human Malignant Glioma Cells can be Blocked by Inhibition of the EGFR Downstream Pathways. J Nucl Med Radiat Ther 3:138. doi:10.4172/2155-9619.1000138

\section{Wound healing assay}

Investigation of cell migration capability after irradiation treatment was done by a modified wound healing assay: Briefly, treated and untreated cells were grown to confluent monolayers. Immediately before irradiation the inhibitors LY294002 $(50 \mu \mathrm{M})$ (Calbiochem, Darmstadt, Germany), PD98059 (50 $\mu \mathrm{M})$ (Biomol, Hamburg, Germany), tyrphostin AG1478 (10 $\mu \mathrm{M})$ (Merck, Darmstadt, Germany) and the stimulator epidermal growth factor (EGF) $(10 \mathrm{ng} / \mathrm{ml})$ (Upstate, Billerica, USA) were added to the medium. Next, the monolayers were wounded by scratching the surface as uniformly as possible with a pipette tip and irradiated. This initial wounding $(0 \mathrm{hr})$ and the movement of the cells in the scratched area were photographically monitored. 12 hrs after irradiation all cells and migrating cells were counted. The following formula shows the calculation of the migration index: $\mathrm{MI}=$ $\left(\mathrm{M}-\left(\mathrm{Mx}\left(\left(\mathrm{T}_{2}-\mathrm{T}_{1}\right) / \mathrm{T}_{1}\right)\right) / \mathrm{T}_{1}\right) \times 100\left(\mathrm{MI}\right.$ : migration index, $\mathrm{T}_{1}$ : cell number at $0 \mathrm{hr}, \mathrm{T}_{2}$ : cell number at $12 \mathrm{hr}, \mathrm{M}$ : migrating cells). The migration index had to be corrected by considering the proliferation rate of cells, because proliferating cells push into the scratched area mimicking an artificial migration. Therefore we calculated the proliferation index and substracted this index from the migration index.

The proliferation index was calculated by the following formula: $\mathrm{PI}=\left(\left(\mathrm{T}_{2}-\mathrm{T}_{1}\right) / \mathrm{T}_{1}\right) \times 100$ (PI: proliferation index, $\mathrm{T}_{1}$ : cell number at $0 \mathrm{hr}$, $\mathrm{T}_{2}$ : cell number at $12 \mathrm{hr}$ ).

\section{Proliferation assessment}

The MTT [3-(4,5-dimethylthiazol-2-yl)-2,5-diphenyltetrazolium bromide] assay was used to assess cell proliferation (Roche Diagnostics $\mathrm{GmbH}$, Penzberg) as previously described [12]. Therefore the cells were plated into 96-well plates at a concentration of 1000 cells/well. The above mentioned inhibitors were added 12 hours prior to irradiation. Cells were incubated 12, 24 and $72 \mathrm{hrs}$ after radiation. Then $10 \mu \mathrm{l}$ of the MTT solution was added to each well, and the cells were incubated at $37^{\circ} \mathrm{C}$ for about $4 \mathrm{hrs}$. Subsequently, $100 \mu \mathrm{l}$ of dimethyl sulfoxide was added to each well, yielding purple solution. The optical density was measured at $590 \mathrm{~nm}$ using an ELISA reader (ASYS Hitech $\mathrm{GmbH}$, Eugendorf).

\section{Immunoblot analysis}

$24 \mathrm{hrs}$ after irradiation cells were harvested in lysis buffer (Cell Lysis Buffer, New England Biolabs, Ipswich, USA) at $4^{\circ} \mathrm{C}$. Lysate was centrifuged $(10000 \mathrm{rpm})$ for $15 \mathrm{~min}$ at $4^{\circ} \mathrm{C}$ to remove insoluble components. Protein concentration was quantified by the Bio-Rad Dc protein assay. Equal amounts of protein were separated on SDS-PAGE $10 \%$ gels. Proteins were transferred to Immobilon-P PVDF membrane (Millipore, Billerica, USA). The membrane was blocked with 5\% nonfat dry milk in Tris-buffered saline containing $0.1 \%$ Tween 20 (TBST). The membrane was then incubated with primary antibody in 5\% nonfat dry milk in TBST, followed by secondary antibody linked to rabbitradish peroxidase diluted in 5\% nonfat dry milk in TBST. ECL Detection System for Western blot Analysis (Amersham, Freiburg, Germany) was followed according to the manufacturer's instructions for antibody detection. The Imager SRX-101 ${ }^{\circ}$ (Konica Minolta, Langenhagen, Germany) was used to detected bands of appropriate sizes.

The following antibodies were used: phospho-EGFR, EGFR, phospho-PKB/Akt (Ser473), PKB/Akt (Ser473), phospho-p44/42 MAPK (Thr202/Tyr204), and p44/42 MAPK (Thr202/Tyr204) from Cell Signaling Technology, Boston, USA at a dilution of 1:1000.

\section{Statistical analysis}

The effect of the radiation dose on migration/proliferation in control cells was assessed in a linear regression model with the migration/proliferation as dependent variable and the radiation dose as a metric predictor. The potential inhibition or enhancement of radiation-based migration/proliferation was investigated based on a generalized least squares model fitted with the R function 'gls' with the migration/proliferation as dependent variable. The predictors were: the radiation dose (metric predictor, coefficient $\beta_{\mathrm{rad}}$ ), the stimulus (categorical predictor with coefficients $\beta_{\mathrm{PD}}, \beta_{\mathrm{LY}}$, etc. and controls as reference category), and their interactions (coefficients $\beta_{\text {rad.PD' }} \beta_{\text {rad. }}$ ${ }_{L Y}$, etc.). A compound symmetry correlation structure was assumed within each experiment. The coefficients were tested based on the Wald test. Separate analyses were conducted for the three cell lines LN18, LN229 and LNZ308. All statistical analyses were performed using the R statistical software (www.r-project.org), version 2.8.1.

\section{Results}

\section{Radiation induces migration and decreases proliferation}

First we tested the migration and proliferation behavior with and without radiation in 3 cell lines (LN18, LN229, LNZ308) by the acute wound healing assay. The cells were irradiated with increasing doses of $2 \mathrm{~Gy}, 5 \mathrm{~Gy}$ and $8 \mathrm{~Gy}$ and monitored for $72 \mathrm{hrs}$. We found a dosedependent increase of migrating cells in all 3 cell lines after irradiation (Figure 1) (tested hypothesis $\beta_{\mathrm{rad}}=0$; LN18: $\mathrm{p}<0.001$, LN229: $\mathrm{p}=0.028$, LNZ308: $\mathrm{p}=0.083$ ). In contrast, proliferation was dose-dependently decreased by radiation, using the proliferation index by the wound healing assay (tested hypothesis $\beta_{\text {rad }}=0 ; \mathrm{LN} 18: \mathrm{p}=0.008$, LN229: $\mathrm{p}=0.42$, LNZ308: $\mathrm{p}=0.59$ ).

\section{EGF receptor is not involved in radiation induced migration}

Stimulation of the EGF receptor by EGF showed no apparent increase of migrating cells after EGF application. Accordingly, inhibition of the EGF receptor by adding the EGFR-inhibitor AG1478 showed no modification in cell migration.



Figure 1: The numbers of migrating cells after irradiation with $0,2,5$ and $8 \mathrm{~Gy}$ were determined by the wound healing assay for the glioma cell lines LN18, LN229 and LNZ308. Cells were grown to confluent monolayers, wounded by scratching the surface as uniformly as possible with a pipette tip and afterwards irradiated. The number of migrated tumor cells in the wound was determined. The means of 4 tests per time point and dose were calculated after 12 hrs. 
Citation: Pickhard A, Margraf J, Piontek G, Knopf A, Reiter R, et al. (2012) The Radiation Induced Migration of Human Malignant Glioma Cells can be Blocked by Inhibition of the EGFR Downstream Pathways. J Nucl Med Radiat Ther 3:138. doi:10.4172/2155-9619.1000138

\section{EGFR downstream pathways mediate radiation induced migration}

The inhibition of PI3-kinase with LY294002 reduced the radiationinduced migration (tested hypothesis $\beta_{\text {rad.LY }}=0 ; \quad$ LN18: $<<0.001$, LN229:p=0.16, LNZ308:p=0.13). Furthermore we found a significant decrease of radiation-induced migration with isochronic inhibition of MEK1 by PD98059 (tested hypothesis $\beta_{\text {rad.PD }}=0$; LN18: $\mathrm{p}=0.036$, LN229: $\mathrm{p}=0.021$, LNZ308: $\mathrm{p}=0.021$ ) (Figure 2).

\section{Inhibition and simultaneously radiation reduce proliferation marginally}

By a MTT test we found a diminution of proliferation by inhibition of the pathways. In this context LY294002 offered main consequence at the proliferation. PD98059 was less effective. After EGF stimulation and simultaneously radiation we could show an increase of proliferating cells (Figure 3). These results were confirmed with the proliferation issues of the wound healing assay.

\section{EGF receptor is not phosphorylated by radiation}

Summarizing the results, it was shown that radiation did not activate the EGF receptor. No difference between irradiated and untreated cells was seen on protein level by western blot analysis for the markers phospho-PKB/Akt and phospho-MAP-kinase. In detail, after inhibition with LY294002 a decrease of phospho-PKB/Akt was observed. The inhibition of MEK1 with PD98059 caused a decrease of phospho-MAP-kinase in all three cell lines.

\section{Discussion}

The EGF receptor, that is overexpressed in many tumor entities, is involved in bad prognosis and shortened overall survival $[13,14]$. Some studies also showed that EGFR overexpression is correlated with a worse response to radiation and chemotherapy $[15,16]$. As it was also shown that the EGF receptor was activated through autophoshorylation after radiation [17]. We focused on this receptor and investigated its possible contribution to radiation induced migration.

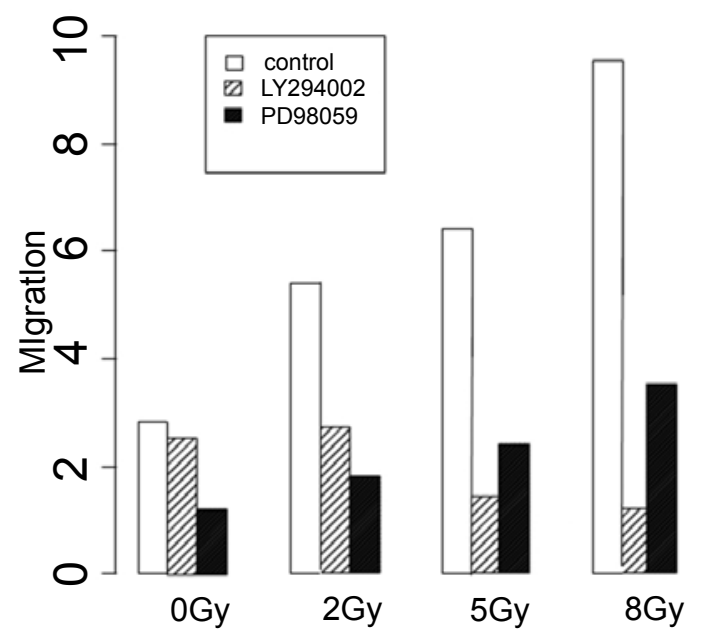

Figure 2: Migration ability of the glioma cell lines after blocking of the downstream pathways of the EGFR: PI3K by LY294002 and MEK1 by PD98059 after irradiation with 0, 2, 5 and 8Gy after 12 hours.

Measurements were made in 4 experiments. Radiation-induced migration was significantly blocked by inhibitors of the downstream pathways of EGFR.
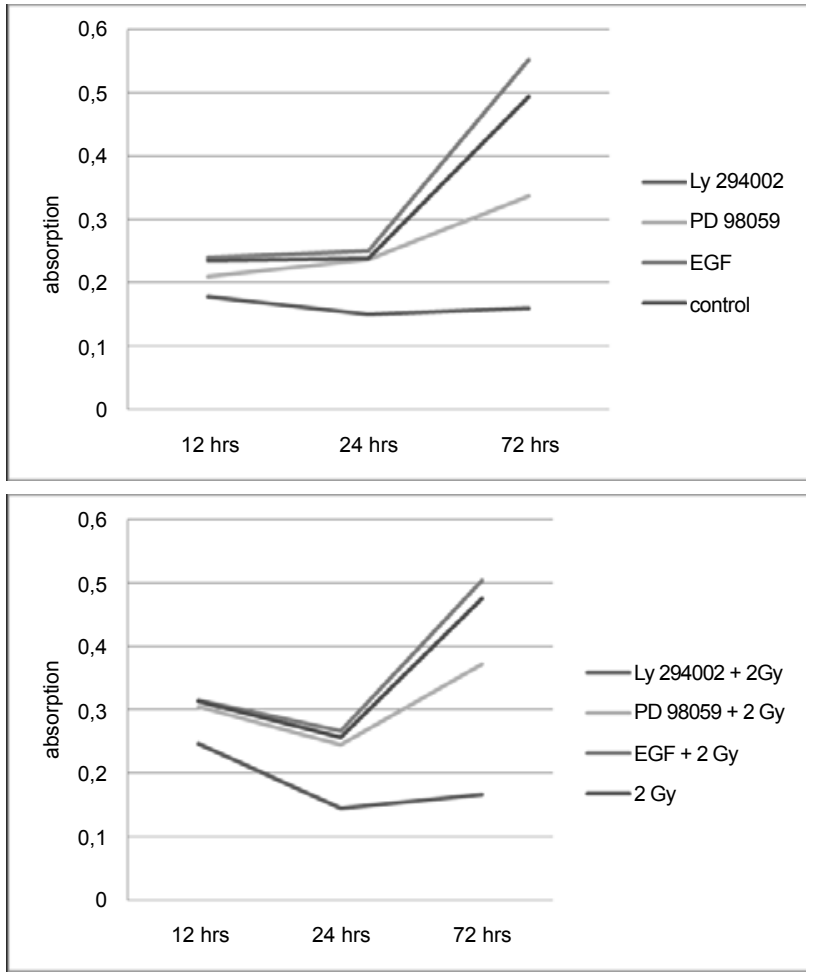

Figure 3: Proliferation was assessed by the MTT test 12 hrs, 24 hrs and 72 hrs after irradiation with 2Gy or without irradiation (0Gy), control.

Proliferation subsided by radiation of the cell line LN229 and also by inhibition of the downstream pathways of the EGFR: PI3K by LY294002 and MEK1 by PD98059, control.

We could not find significant inhibition of migration cells after treatment with EGFR inhibitor AG1478. Also we saw no activation of the EGFR in western blot assays after stimulation with EGF or radiation. Therefore, we assume that the EGF receptor seems to be irrelevant for the radiation induced migration.

It is known that the autophosphorylation of the EGF receptor produces an activation of the downstream signal pathways [16-19] and it was reported that the PI3K pathway seems to be responsible for migration [20,21]. So we focused on the downstream pathways of EGFR, the PI3K and the MAPK pathway.

Analyses of the pathways downstream EGFR gave the following results: inhibition of the PI3K by LY294002 showed a decrease of migrating cells. The inhibition of MEK1 by PD98059 showed manifestly a decrease of migration. When blocking the downstream pathways of EGFR the biggest impact on inhibition of proliferation was found by using the PI3K inhibitor LY294002. However, there was no significance. The MEK1 inhibitor PD98059 was less effective.

Further studies identified PI3K as regulator of the cellular answer to ionizing rays. Thereby, the inhibitor of the PI3K, LY294002 boost the antineoplastic effect of the simultaneous radiation [22-24], which was also found in our study in proliferation assays. In addition, we observed the inhibitory effect of PD98059 at migration under radiation doses. Li et al. found that the activation of MAPK by radiation was not only caused by phosphorylation of the EGFR [25] but also through a Src-dependent pathway. This might be the reason why migration is 
Citation: Pickhard A, Margraf J, Piontek G, Knopf A, Reiter R, et al. (2012) The Radiation Induced Migration of Human Malignant Glioma Cells can be Blocked by Inhibition of the EGFR Downstream Pathways. J Nucl Med Radiat Ther 3:138. doi:10.4172/2155-9619.1000138

primarily decreased by inhibition with PD98059. Furthermore, Hwang et al. [26] could show that PD98059 has no impact on migration without radiation.

As glioma cells typically invade the surrounded area, the microsurgical exstirpation in combination with adjuvant irradiation therapy is the gold standard [27] and radiation induced migration becomes clinically relevant. In the last few years, many attempts were made for optimizing radiotherapy, such as increasing the dose (over 60Gy yield), whole brain irradiation, and the adoption of a stereotactic therapy $[28,29]$. Unfortunately, all these therapy concepts led to an increase of recrudescences in the surrounding area and a combination with chemotherapy must be discussed.

\section{Conclusion}

Glioblastoma cannot be removed completely because of the infiltrative growth in the surrounded area. The edge and infiltrative zone are the main problems because most recurrences extinguish there. Therefore, radiation therapy is applied but the effect is mostly temporary. Also, recent studies show an increase of migrating cells.

We found a dose dependent reduction of proliferation but an increase of migration after experimental irradiation of glioma cells. The radiation induced migration could be blocked by LY294003, a PI3K inhibitor and PD98059, a MEK1 inhibitor. Also, we observed that inhibition of the EGFR was not effective.

Therefore we postulate that the downstream pathways and not the EGFR itself might be responsible for the radiation induced migration in glioma.

\section{References}

1. Tran NL, McDonough WS, Savitch BA, Fortin SP, Winkles JA, et al. (2006) Increased fibroblast growth factor-inducible 14 expression levels promote glioma cell invasion via Rac1 and nuclear factor-kappaB and correlate with poor patient outcome. Cancer Res 66: 9535-9542.

2. Fine HA, Dear KB, Loeffler JS, Black PM, Canellos GP (1993) Meta-analysis of radiation therapy with and without adjuvant chemotherapy for malignant gliomas in adults. Cancer 71: 2585-2597.

3. Stupp R, Hegi ME, Gilbert MR, Chakravarti A (2007) Chemoradiotherapy in malignant glioma: standard of care and future directions. J Clin Oncol 25: 4127 4136.

4. Walbert T, Mikkelsen T (2011) Recurrent high-grade glioma: a diagnostic and therapeutic challenge. Expert Rev Neurother 11: 509-518.

5. Wild-Bode C, Weller M, Rimner A, Dichgans J, Wick W (2001) Subletha irradiation promotes migration and invasiveness of glioma cells: implications for radiotherapy of human glioblastoma. Cancer Res 61: 2744-2750.

6. Shinojima N, Tada K, Shiraishi S, Kamiryo T, Kochi M, et al. (2003) Prognostic value of epidermal growth factor receptor in patients with glioblastoma multiforme. Cancer Res 63: 6962-6970.

7. Wang Y, Barbacioru C, Hyland F, Xiao W, Hunkapiller KL, et al. (2006) Large scale real-time PCR validation on gene expression measurements from two commercial long-oligonucleotide microarrays. BMC Genomics 7: 59

8. Saito T, Hama S, Kajiwara Y, Sugiyama K, Yamasaki F, et al. (2006) Prognosis of cerebellar glioblastomas: correlation between prognosis and immunoreactivity for epidermal growth factor receptor compared with supratentorial glioblastomas. Anticancer Res 26: 1351-1357.

9. Testa JR, Bellacosa A (2001) AKT plays a central role in tumorigenesis. Proc Natl Acad Sci USA 98: 10983-10985.
10. Tamura M, Gu J, Matsumoto K, Aota S, Parsons R, et al. (1998) Inhibition of cell migration, spreading, and focal adhesions by tumor suppressor PTEN. Science 280: 1614-1617.

11. Ishii N, Maier D, Merlo A, Tada M, Sawamura Y, et al. (1999) Frequent coalterations of TP53, p16/CDKN2A, p14ARF, PTEN tumor suppressor genes in human glioma cell lines. Brain Pathol 9: 469-479.

12. Alley MC, Scudiero DA, Monks A, Hursey ML, Czerwinski MJ, et al. (1988) Feasibility of drug screening with panels of human tumor cell lines using a microculture tetrazolium assay. Cancer Res 48: 589-601.

13. Milas L, Mason K, Hunter N, Petersen S, Yamakawa M, et al. (2000) In vivo enhancement of tumor radioresponse by $\mathrm{C} 225$ antiepidermal growth factor receptor antibody. Clin Cancer Res 6: 701-708.

14. Reardon DB, Contessa JN, Mikkelsen RB, Valerie K, Amir C, et al. (1999) Dominant negative EGFR-CD533 and inhibition of MAPK modify JNK1 activation and enhance radiation toxicity of human mammary carcinoma cells Oncogene 18: 4756-4766.

15. Ang KK, Berkey BA, Tu X, Zhang HZ, Katz R, et al. (2002) Impact of epiderma growth factor receptor expression on survival and pattern of relapse in patients with advanced head and neck carcinoma. Cancer Res 62: 7350-7356.

16. Barker FG 2nd, Simmons ML, Chang SM, Prados MD, Larson DA, et al. (2001) EGFR overexpression and radiation response in glioblastoma multiforme. Int J Radiat Oncol Biol Phys 51: 410-418.

17. Kimura T, Holland WS, Kawaguchi T, Williamson SK, Chansky K, et al. (2004) Mutant DNA in plasma of lung cancer patients: potential for monitoring response to therapy. Ann N Y Acad Sci 1022: 55-60.

18. Arteaga CL (2002) Epidermal growth factor receptor dependence in human tumors: more than just expression? Oncologist 7: 31-39.

19. Rak J, Filmus J, Finkenzeller G, Grugel S, Marmé D, et al. (1995) Oncogenes as inducers of tumor angiogenesis. Cancer Metastasis Rev 14: 263-277.

20. Meng Q, Xia C, Fang J, Rojanasakul Y, Jiang BH (2006) Role of PI3K and AKT specific isoforms in ovarian cancer cell migration, invasion and proliferation through the p70S6K1 pathway. Cell Signal 18: 2262-2271.

21. Zheng ZZ, Liu ZX (2007) Activation of the phosphatidylinositol 3-kinase/protein kinase Akt pathway mediates CD151-induced endothelial cell proliferation and cell migration. Int J Biochem Cell Biol 39: 340-348.

22. Gupta AK, Cerniglia GJ, Mick R, Ahmed MS, Bakanauskas VJ, et al. (2003) Radiation sensitization of human cancer cells in vivo by inhibiting the activity of PI3K using LY294002. Int J Radiat Oncol Biol Phys 56: 846-853.

23. Rosenzweig KE, Youmell MB, Palayoor ST, Price BD (1997) Radiosensitization of human tumor cells by the phosphatidylinositol3-kinase inhibitors wortmannin and LY294002 correlates with inhibition of DNA-dependent protein kinase and prolonged G2-M delay. Clin Cancer Res 3: 1149-1156.

24. Shi YQ, Blattmann $H$, Crompton NE (2001) Wortmannin selectively enhance radiation-induced apoptosis in proliferative but not quiescent cells. Int J Radia Oncol Biol Phys 49: 421-425.

25. Li Z, Hosoi Y, Cai K, Tanno Y, Matsumoto Y, et al. (2006) Src tyrosine kinase inhibitor PP2 suppresses ERK1/2 activation and epidermal growth facto receptor transactivation by X-irradiation. Biochem Biophys Res Commun 341: 363-368.

26. Hwang SY, Jung JW, Jeong JS, Kim YJ, Oh ES, et al. (2006) Dominant-negative Rac increases both inherent and ionizing radiation-induced cell migration in C6 rat glioma cells. Int J Cancer 118: 2056-2063.

27. Nieder C, Mehta MP, Jalali R (2009) Combined radio- and chemotherapy of brain tumours in adult patients. Clin Oncol (R Coll Radiol) 21: 515-524.

28. Hess CF, Schaaf JC, Kortmann RD, Schabet M, Bamberg M (1994) Malignant glioma: patterns of failure following individually tailored limited volume irradiation. Radiother Oncol 30: 146-149.

29. Mornex F, Nayel H, Taillandier L (1993) Radiation therapy for malignant astrocytomas in adults. Radiother Oncol 27: 181-192. 